\title{
Venous ulcer treatment requires inelastic compression
}

\section{G. Mosti}

Head of Angiology Department, Clinica MD Barbantini, Lucca, Italy

\begin{abstract}
Keywords
Venous leg ulcers, ulcer healing rate, compression therapy, elastic compression, inelastic compression, venous reflux, venous pumping function, venous hemodynamic impairment
\end{abstract}

\section{Summary}

Leg ulcers have a venous pathophysiology in the vast majority of cases (1-4). Superficial or deep venous insufficiency and deep vein obstruction produce ambulatory venous hypertension due to venous reflux and venous pumping function impairment. The impaired venous hemodynamics is the key pathophysiologic mechanism leading to skin damage through several intermediate steps. Fibrin cuff formation around the microvessels, impairing gases $\left(\mathrm{O}_{2}, \mathrm{CO}_{2}\right)$ exchange (5), white cells entrapment (6) causing skin necrosis, growth factors inhibition (7) producing a stagnation of the healing process have been considered involved in ulcer onset and maintenance. The treatment of venous leg ulcers (VLU) must be based on the correction of the hemodynamic impairment which can be achieved conservatively by means of compression therapy, walking and leg elevation or by means of invasive procedures (open surgery, endovascular procedures as endovenous Laser ablation, radiofrequency, foam sclerotherapy, conservative hemodynamic treatment). Compression therapy is frequently considered the first treatment option and it is the only therapeutical procedure which achieved the grade $1 \mathrm{~A}$ in most recent guidelines or consensus documents (8-10). The crucial point is choosing the most effec-

Korrespondenzadresse

Giovanni Mosti, Angiology Department, MD Barbantini Clinic

Via del Calcio 2; 5510 Lucca; Italy

Tel. +39058391971

$\mathrm{Fax}+390583490050$

E-Mail: giovanni.mosti10@gmail.com tive compression modality. There are clear evidences that inelastic is more effective than elastic material in counteracting the venous hemodynamic impairment (11-14) that should "ensure" a superior effectiveness in promoting a higher healing rate of VLU, which are due to venous hemodynamic impairment. When looking at evidences we have some data showing that the higher the compression pressure the higher the healing rate $(9,15-17)$ and this is clearly in favors of inelastic bandages which exert a much higher pressure that elastic materials. On the other side we have many papers claiming a greater effectiveness of elastic stockings or elastic bandaged compared with inelastic material (18-30). Nevertheless studies comparing elastic and inelastic devices have so many flaws that their conclusions are hard to trust (31). Aim of this work is providing updated information about compression therapy effects on venous hemodynamic and the most effective compression modality to achieve the best outcome in VLU treatment.

\section{Schlüsselwörter}

Ulcus cruris venosum, Heilungsrate von Ulzera, Kompressionstherapie, elastische Kompression, inelastische Kompression, venöser Reflux, venöse Pumpfunktion, venöse hämodynamische Beeinträchtigung

\section{Zusammenfassung}

Beinulzera haben in der überwiegenden Mehrzahl der Fälle eine venöse Pathophysiologie (1-4). Eine oberflächliche oder tiefe venöse In-

Die Behandlung von venösen Ulzera erfordert eine unelastische Kompression

Phlebologie 2018;47: 7-12

https;//doi.org/10.12687/phleb2406-1-2018

Eingereicht: 04. Dezember 2017

Angenommen: 04. Dezember 2017 suffizienz und eine tiefe Venenobstruktion führen zu einer ambulanten venösen Hypertonie aufgrund einer venösen Reflux- und venösen Pumpfunktionsstörung. Die gestörte venöse Hämodynamik ist der wichtigste pathophysiologische Mechanismus, der durch mehrere Zwischenschritte zu Hautschäden führt. An der Ulkus-Entstehung und UlkusUnterhaltung scheinen beteiligt zu sein: $\mathrm{Fi}$ brin-Manschetten-Bildung um die Mikrogefäße, Beeinträchtigung des Gasaustauschs $\left(\mathrm{O}_{2}, \mathrm{CO}_{2}\right)(5)$, Einklemmung weißer Zellen (6) (verursacht Hautnekrose), Hemmung der Wachstumsfaktoren (7), welche eine Stagnation des Heilungsprozesses verursacht. Die Behandlung von venösen Beinulzera (VLU) muss auf der Korrektur der hämodynamischen Beeinträchtigung beruhen, die konservativ mittels Kompressionstherapie, Gehen und Beinheben oder mittels invasiver Verfahren erreicht werden kann (offene Chirurgie, endovaskuläre Eingriffe als endovenöse Laserablation, Radiofrequenz-, Schaum-Sklerotherapie, konservative hämodynamische Behandlung). Die Kompressionstherapie wird häufig als erste Behandlungsoption angesehen und ist das einzige therapeutische Verfahren, das in neueren Leitlinien oder Konsensusdokumenten die Stufe $1 \mathrm{~A}$ erreichte (8-10). Der entscheidende Punkt ist die Auswahl der effektivsten Kompressionsmodalität. Es gibt eindeutige Hinweise darauf, dass unelastisches Material wirksamer ist als elastisches Material, um der venösen hämodynamischen Beeinträchtigung entgegenzuwirken (11-14), die eine höhere Wirksamkeit bei der Förderung einer höheren Heilungsrate von VLU gewährleisten sollte, die auf eine venöse hämodynamische Beeinträchtigung zurückzuführen ist. Wenn wir uns die Evidenz anschauen, haben wir einige Daten, die zeigen, dass je höher der Kompressionsdruck ist, desto höher die Heilungsrate $(9,15-17)$. Dies spricht eindeutig für unelastisches Material, welches einen viel höheren Druck ausübt als elastische Materialien. Auf der anderen Seite 
haben wir viele Studien, die eine größere Wirksamkeit von elastischen Strümpfen oder elastischen Bandagen im Vergleich zu unelastischem Material (18-30) behaupten. Dennoch haben Studien, in denen elastisches und unelastisches Material verglichen werden, so viele Mängel, dass ihre Schlussfolgerungen schwer zu glauben sind (31). Ziel dieser Arbeit ist es, aktuelle Informationen über die Auswirkungen der Kompressionstherapie auf die venöse Hämodynamik und die effektivste Kompressionsmodalität bereitzustellen, um das beste Ergebnis bei der VLU-Behandlung zu erzielen.

\section{Impaired venous hemodynamics}

The venous pressure in the legs depends on body position. It is very low in supine position, it increases in the sitting position and it is maximal in standing position (about $70-80 \mathrm{~mm} \mathrm{Hg}$ ) both in normal individuals and in patients with venous disease. In normal subjects, muscle pumps and valvular function fragmenting the blood column get a significant pressure decrease to 20-30 during active movements (e.g. walking) (32). In patients with venous insufficiency, valves failure cause the column of standing blood in the vein to remain unbroken even during ambulation. Under these circumstances a minimal hydrostatic pressure decrease occurs or it can even increase during and immediately after ambulation in case of venous obstruction: this is what we call Ambulatory Venous Hypertension (AVH), which causes venous congestion.

\section{Effectiveness of compression therapy in
counteracting AVH}

Compression therapy increases the transmural pressure increasing the extravenous pressure so narrowing or occluding the leg veins. This is the prerequisite for the hemodynamic effectiveness of compression therapy but venous narrowing-occlusion can be possible only by applying an external pressure of the same magnitude or higher than intravenous pressure. Actually, it has been shown that due to different venous pressure in different body positions, a low external pressure in the range of 20 $\mathrm{mm} \mathrm{Hg}$ is able to narrow or occlude the veins in the supine position, but the compression pressure must rise to $50 \mathrm{~mm} \mathrm{Hg}$ in the sitting position and to close to $70-80$ $\mathrm{mm} \mathrm{Hg}$ in the standing position $(33,34)$ (that was defined as very strong in a recent consensus paper) (35) to exert the same effect. Such high external pressure approaching or overcoming the intravenous pressure may produce a vein occlusion at every step during physical activity so restoring a kind of valve mechanism which reduces the AVH (14) by reducing the venous reflux $(10,11)$ and increasing the calf pumping function $(12,13)$.

\section{Which compression material is able to counteract AVH}

All compression devices are basically made up with elastic or inelastic material. When wrapped on the leg they exert a compression pressure which, according to the Laplace law, depends on the stretch applied to the bandage, the number of turns and the radius of the leg-segment (36).

The two materials have completely different physical characteristics.

The elastic or long stretch material (represented by elastic stockings or elastic bandages with an extensibility higher stretch than $100 \%$ ) gives way to the muscle expansion that occurs during standing and physical activity, resulting a very low pressure difference between the resting and standing or walking conditions. This difference, that was named Static Stiffness Index (SSI), is lower than $10 \mathrm{~mm} \mathrm{Hg}$ with elastic materials $(37,38)$. Also the difference between diastolic and systolic pressure during muscular activity, responsible of the so called „massaging effect“ (39) of compression devices over the calf muscle, is very low. These characteristics are consistently maintained independently on applied pressure and material (if elastic stockings or elastic bandages) producing quite a sustained pressure. In addition, elastic material tends to regain its initial length when stretched and this "return force " is directly related to the stretch applied to the bandage. The "squeezing effect" of a too stretched elastic material can be painful and not tolerated by the patients after a short time from application. As a consequence, when properly stretched, an elastic bandage will exert a supine pressure of 30-40 mm Hg. This pressure will rise by less than $10 \mathrm{~mm} \mathrm{Hg}$ in standing position and will never approach the intravenous pressure resulting unable to narrow or occlude the veins and to exert a hemodynamic effect ( Fig. 1, 2). When we want to use elastic material to exert a very strong pressure in standing position, necessary to occlude the leg veins, elastic bandages must be applied with strong stretch ( $>$ Fig. 3 ) or several elastic stockings must be superimposed: in both these circumstances also the supine pressure will be very strong. The bandage will exert a very strong continuous pressure, which, in addition to the "squeezing effect" of these materials, will make very painful and poorly tolerated the compression system, as reported.

Advantage of elastic materials: they are easy to apply, usually as single component.

The inelastic material (short stretch or inextensible bandages, Velcro ${ }^{\circledR}$ devices, hybrid pumps) exerts its effect by resisting the increase of muscle volume during muscular contraction in standing position and during physical activity (the leg will give way) so producing higher peak pressures when standing or walking compared with elastic, long-stretch devices. Inelastic material doesn't have any elastic fiber and doesn't have any return force: it doesn't "squeeze" and can be applied with full stretch.

The modern composite, multilayer and multicomponent, inelastic bandages, including a padding layer with the inelastic material as last component, exert a relatively low and well tolerated pressure at rest but a much higher pressure often higher than $70 \mathrm{~mm} \mathrm{Hg}$ during standing and walking. The SSI is always $>10$, which characterizes the inelastic range. The intermittently strong or very strong pressure peaks during muscular exercise will over- 
come the intravenous pressure intermittently occluding the vein and so restoring a kind of valve mechanism (14) ( $>$ Fig. 4).

In a few words the inelastic material is able to adapt to the body position by exerting a relatively low pressure in the resting position (comfortable) and a strong or very strong pressure in standing position and during muscle activity (effective) coming close to an ideal compression device (40).

Unfortunately the multilayer, multicomponent inelastic bandages are difficult to apply and require expert and well educated personnel. In a series of papers it was demonstrated that only from 10 to $60 \%$ (depending on the paper) of expert healthcare providers treating ulcer patients were able to apply the target pressure with different inelastic bandages (41-45).

\section{Hemodynamic effects of compression materials}

The different physical properties of elastic and inelastic materials result in completely different effects on venous hemodynamics.

Inelastic is significantly more effective than elastic material in:

- reducing venous reflux both in patient with deep venous (10) or superficial venous incompetence (11).

- improving the venous pumping function severely reduced in venous insufficiency (12-13).

- reducing AVH (14).

Inelastic material is able to reduce venous reflux and increase venous pumping function even at a low/mild pressure range of 20-40 mm Hg (46) which has an important implication when inelastic compression necessary to improve venous hemodynamics loses pressure or must be applied with reduced pressure in patients mixed artero-venous ulcers.

Finally inelastic material maintains its hemodynamic effect overtime despite of a significant pressure drop as the stiffness of the bandage is well maintained as proved by the unchanged SSI and "massaging effect" (47).

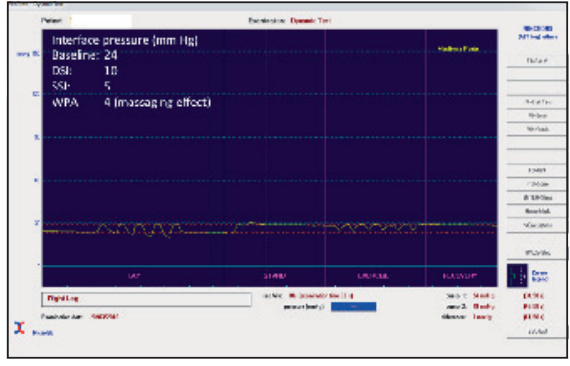

Fig. 1 Elastic stocking compression pressure record. Compression pressure increase by dorsiflexions, standing up and walking is very small: sustained pressure. DSI: Dynamic Stiffness index is the difference between diastolic and systolic pressure performing foot dorsiflexions in supine position; SSI: Static Stiffness Index is difference between standing and supine position. WPA: walking pressure amplitude is the difference between systolic and diastolic pressure while walking.

\section{Which compression material for VLU}

No doubt that inelastic material, exerting strong or very strong pressure, is an effective treatment modality to get the highest healing rate when looking for the best treatment option.

When correctly applied to exert a strong pressure inelastic bandages can achieve an ulcer healing rate close to $100 \%$ in three months treatment(48).

Based on clinical and hemodynamic data, is not easy to understand why many reports claim the superiority of elastic (both elastic stockings and elastic bandages) compared to inelastic material in improving the VLU healing rate (17-30). Nevertheless it is important to underline many methodological flaws of these studies.

Compression therapy exerts its effects by providing compression pressure to the leg. Compression pressure is the dosage of compression therapy but, contrarily to any other field in medicine, the compression dosage has almost never been measured and reported when dealing with compression therapy even if compression pressure measurement is easy to perform with accurate and cheap devices $(49,50)$.

Not measuring compression pressure it is impossible to know if the bandages were correctly applied. They could have been

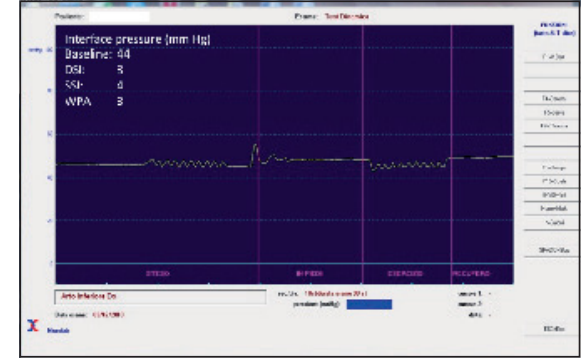

Fig. 2 Elastic bandage compression pressure record. The dynamic characteristics are the same as elastic stockings or kits.

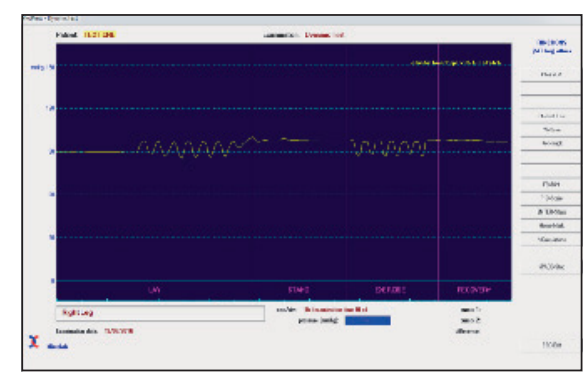

Fig. 3 Pressure curve of an elastic bandage applied with high stretch to exert a very strong standing pressure. It can be noticed that also the supine pressure is very strong due to the physical characteristics of elastic material. This strong and sustained pressure is painful and intolerable by the patient.

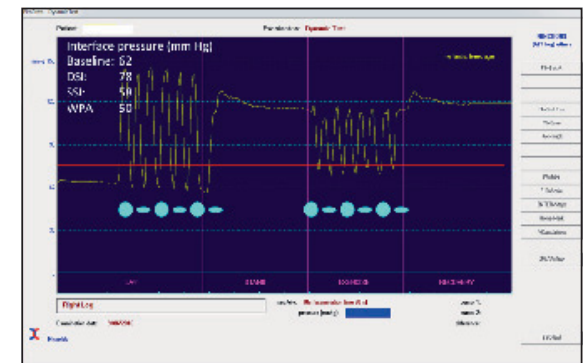

Fig. 4 Pressure curve of an inelastic bandage exerting a supine pressure of $60 \mathrm{~mm} \mathrm{Hg}$. Compression pressure increase by dorsiflexions, standing up and walking is very high: intermittent compression with high pressure peaks that overcome the intravenous pressure (represented by the red line) restoring a kind of valvular function.

applied too stretched, so being painful and dangerous, and forcing the patients to remove them, or too loose, so being ineffective.

In addition not measuring the pressure or calculating the SSI produced an amazing mistake in almost all studies comparing elastic and inelastic bandages. 
In these studies (17-24) the prototype of elastic material is the so called Four Layer Bandage which was considered elastic by definition as it is made up of four different elastic components. Nevertheless measuring supine and standing pressure and calculating the SSI of the final bandage, it was possible to show that SSI is in the inelastic range. It may happen that the superimposition of different components and the friction between the layers change the elastic properties of the final bandage, making it a highly stiff device (51). In conclusion all these studies report a comparison between two different inelastic compression devices and the reported different outcomes in terms of healing rate may depend on of the greater experience of dedicated personnel in applying the Four Layer Bandage.

Also the second comparison, inelastic bandages vs elastic stockings, has many major flaws.

First of all it has to be underlined that the elastic stockings taken into consideration for comparison are actually elastic kits or tubular devices exerting a supine pressure of $40 \mathrm{~mm} \mathrm{Hg}$ or more and higher stiffness compared to a single stocking (although always in the range of elastic material) due to the friction between the 2 components (25-30). In addition the subbandage pressure was, once again, not measured and the skillness of "bandagers" not reported. In these studies we may roughly know the pressure of elastic kits which is declared by the producer but we do not have any information on the pressure of inelastic bandage that can be extremely variable $(52,53)$ as it only depends on the health personnel skillness which is usually poor (41-45). As a consequence it could well be that a good elastic kit, also named "ulcer kit", was compared with a poorly applied bandage.

In a few studies where compression pressure is measured $(16,29,54)$ it was demonstrated that the higher the pressure the higher the healing rate and this conclusion is in favor of inelastic bandages even despite of the conclusion of author's papers. In fact, as well proved, inelastic bandages, when correctly applied, exert a compression pressure definitely higher than elastic material.

Velcro devices may replace inelastic bandages providing an effective and cost effective VLU treatment modality.

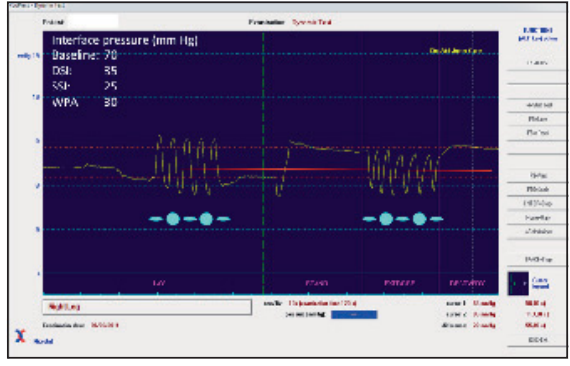

Fig. 5 Pressure curve exerted by a Velcro device designed for ulcer treatment. Also with this device compression pressure increase by dorsiflexions, standing up and walking is high overcoming the intravenous pressure and restoring a kind of valvular function.

When considering indications for compression in VLU treatment, it is also important to consider that compression therapy is not only generally poorly applied but also largely underused even in the western countries, ranging from 15 to $53 \%$ of patients who would need compression (55, 56). Many reasons can explain this lack of implementation of compression therapy in VLU treatment being lack of education in applying inelastic bandages, absence of self-confidence and fear to produce further skin damages some of the most important reasons.

Nowadays we need to consider another treatment option: the adjustable Velcro ${ }^{\circ}$ compression devices (AVCD) which are becoming more and more widespread. These devices have a high SSI (so acting as inelastic material) when applied with strong pressure ( Fig. 5). Only for one of these devices (CircAid, Medi, Bayreuth, Germany) we have data showing it is effective in terms of improvement of the impaired venous hemodynamics $(57,58)$. At the same time, it is very easy to use and can be applied and re-adjusted even by the patients themselves after a very short wearing and education time $(59,60)$ so allowing self management and considerable cost savings. In addition this device has been reported to be more effective and cost effective in achieving VLU healing when compared with Four Layer bandages or with Unna Boot bandage (61-63). Finally it was proved to be more effective than inelastic bandages in phlebo-lymphedema treatment $(59,64)$.

\section{Ulcer recurrence prevention}

VLUs may recur and the recurrence rate may be as high as almost $40 \%$ (65). Surgical correction of superficial venous incompetence was shown to prevent ulcer recurrence significantly more effectively than compression therapy $(66,67)$. Compression therapy is anyway effective in VLU recurrence prevention even if it must be considered as second choice. Elastic stockings are used in this indication with the highest tolerable compression (68). Compliance to compression by elastic stockings is considered even more important that compression pressure (69).

\section{Conclusions}

Compression therapy is the milestone of VLU treatment. Inelastic compression exerts a strong pressure and strong pressure peaks and can restore a kind of valve mechanism so significantly improving the impaired venous hemodynamics. It was proved to be the most effective compression modality to increase the VLU healing rate. Elastic material (bandages or stockings) are claimed to be as or more effective than inelastic material. The reported studies unfortunately are burdened with significant methodological flaws making their conclusions not trustable. Inelastic materials include inelastic bandages and the Velcro ${ }^{\circ}$ devices. There are some evidences that one of these devices is even more effective that inelastic bandages to increase the ulcer healing rate and to treat venous edema and lymphedema. At the same time the device is easy to use and can be directly managed by the patients allowing cost savings. These data will be hopefully confirmed by new studies.

\section{Conflict of interest}

The author declares no conflict of interest.

\section{Ethical guidelines}

The manuscript was prepared according to national guidelines and the current Declaration of Helsinki. 


\section{References}

1. Baker SR, Stacey MC, Singh G, Hoskin SE, Thompson PJ. Aetiology of chronic leg ulcers. Eur J Vasc Surg 1992 May; 6(3): 245-251.

2. Shami SK, Sarin S, Cheatle TR, et al. Venous ulcers and the superficial venous system. J Vasc Surg 1993; 17: 487-490.

3. Adam DJ, Naik J, Hartshorne T, Bello M, London NJ. The diagnosis and management of 689 chronic leg ulcers in a single-visit assessment clinic. Eur J Vasc Endovasc Surg 2003 May; 25(5): 462-468.

4. Körber A, Klode J, Al-Benna S et al. Etiology of chronic leg ulcers in 31,619 patients in Germany analyzed by an expert survey. J Dtsch Dermatol Ges 2011 Feb; 9(2): 116-121.

5. Browse NL, Burnard KG. The cause of venous ulceration. Lancet 1982; 243-245.

6. Coleridge Smith PD, Thomas P, Scurr JH, Dormandy JA. Causes of venous ulceration: a new hypothesis. Br Med J (Clin Res Ed). 1988 Jun 18; 296: 1726-1727.

7. Falanga V, Eaglstein WH. The „trap“ hypothesis of venous ulceration. Lancet 1993 Apr 17; 341(8851): 1006-1008.

8. O'Donnell TF, Passman MA, Marston WA, Ennis WJ, Dalsing M, Kistner RL et al. Management of venous leg ulcers: Clinical practice guidelines of the Society for Vascular Surgery and the American Venous Forum. JVS 2014; 60: 3S-59S.

9. Mosti G, De Maeseneer M, Cavezzi A, Parsi K, Morrison N, Nelzen O et al. Society for Vascular Surgery and American Venous Forum Guidelines on the management of venous leg ulcers: the point of view of the International Union of Phlebology. Int. Angiol 2015; 34 (3): 212-218.

10. Franks PJ, Barker J, Collier M, Gethin G, Haesler E, Jawien A, Laeuchli S, Mosti G, Probst S, Weller C. Management of Patients With Venous Leg Ulcers: Challenges and Current Best Practice. J Wound Care 2016 Jun; 25 (Suppl 6): S1-S67.

11. Mosti G, Partsch H. Duplex scanning to evaluate the effect of compression on venous reflux. Int Angiol 2010 Oct; 29(5): 416-420.

12. Mosti G, Mattaliano V, Partsch H. Inelastic compression increases venous ejection fraction more than elastic bandages in patients with superficial venous reflux. Phlebology 2008; 23(6): 287-294.

13. Mosti G, Partsch H. Measuring venous pumping function by strain-gauge plethysmography. Int Angiol 2010 Oct; 29(5): 421-425.

14. Partsch B, Mayer W, Partsch H. Improvement of ambulatory venous hypertension by narrowing of the femoral vein in congenital absence of venous valves. Phlebology 1992; 7: 101-104.

15. Milic DJ, Zivic SS, Bogdanovic DC, Jovanovic MM, Jankovic RJ, Milosevic ZD, Stamenkovic DM, Trenkic MS. The influence of different sub-bandage pressure values on venous leg ulcers healing when treated with compression therapy. J Vasc Surg 2010 Mar; 51(3): 655-661.

16. Brizzio E, Amsler F, Lun B, Blättler W. Comparison of low-strength compression stockings with bandages for the treatment of recalcitrant venous ulcers. J Vasc Surg 2010; 51: 410-416.

17. Cullum N, Nelson EA, Fletcher AW, Sheldon TA. Compression for venous leg ulcers. Cochrane Database Syst Rev 2001; (2): CD000265.
18. Franks PJ, Moody M, Moffatt CJ et al. Randomised trial of cohesive short-stretch versus four-layer bandaging in the management of venous ulceration. Wound Rep Reg 2004; 12: 157-162.

19. Moffatt CJ, McCullagh L, O'Connor et al. Randomized trial of four-layer bandage systems in the management of chronic venous ulceration. Wound Rep Reg 2003; 11: 166-171.

20. Fletcher A, Cullum N, Sheldon TA. A systematic review of compression treatment for venous leg ulcers. BMJ 1997; 315: 576-580.

21. Callam MJ, Harper DR, Dale JJ et al. Lothian Forth Valley leg ulcer healing trial-part 1: elastic versus non-elastic bandaging in the treatment of chronic leg ulceration. Phlebology 1992; 7: 136-141.

22. Duby T, Hofman D, Cameron J et al. A randomized trial in the treatment of venous leg ulcers comparing short stretch bandages, four layer bandage system, and a long stretch-paste bandage system. Wounds 1993; 5: 276-279.

23. Ukat A, Konig M, Vanscheid W et al. Short stretch versus multilayer compression for venous leg ulcers: a comparison of healing rates. JWC 2003; 12: 139-143.

24. Scriven JM, Taylor LE, Wood AJ et al. A prospective randomised trial of four-layer versus short stretch compression bandages for the treatment of venous leg ulcers. Ann R Coll Surg Engl 1998; 80: 215-220.

25. Nelson EA, Iglesias CP, Cullum N et al. Randomized clinical trial of four-layer and short-stretch compression bandages for venous leg ulcers. $\mathrm{Br} \mathrm{J}$ Surg 2004; 91: 1292-1299.

26. Mariani F, Mattaliano V, Mosti G, Gasbarro V, Bucalossi M, Blättler W. The treatment of venous leg ulcers with a specifically designed compression stocking kit. Phlebologie 2008; 37: 191-197.

27. Junger M, Partsch H, Ramelet AA; Zuccarelli F. Efficacy of a ready-made tubular compression device versus short stretch bandages in the treatment of venous leg ulcers. Wounds 2004; 16: 313-320.

28. Jünger M, Wollina U, Kohnen R, Rabe E. Efficacy and tolerability of an ulcer compression stocking for therapy of chronic venous ulcer compared with a below-knee compression bandage: results from a prospective, randomized, multicentre trial. Curr Med Res Opin. 2004 Oct; 20(10): 1613-1623.

29. Horakova MA, Partsch H. Compression stockings in treatment of lower leg venous ulcer. Wien Med Wochenschr 1994; 144(10-11): 242-249.

30. Amsler F, Willenberg T, Blättler W. Management of venous ulcer: a meta analysis of randomized studies comparing bandages to specifically designed stockings. J Vasc Surg 2009; 50: 668-674.

31. Mosti G. Elastic stockings vs inelastic bandages for ulcer healing: a fair comparison? Phlebology 2012 Feb; 27(1): 1-4.

32. Arnoldi CC. Venous pressure in the leg of healthy human subjects at rest and during muscular exercise in the nearly erect position. Acta Chir Scand 1965; 130(6): 570-583.

33. Partsch B, Partsch H. Calf compression pressure required to achieve venous closure from supine to standing positions. J Vasc Surg 2005; 42: 734-738.

34. Partsch H, Mosti G, Mosti F. Narrowing of leg veins under compression demonstrated by magnetic resonance imaging (MRI). Int Angiol 2010; 29(5): 408-410.
35. Partsch H, Clark M, Mosti G et al. Classification of Compression Bandages: Practical Aspects. Derm Surg 2008; 34: 600-609.

36. Pellicer J, Garcia-Morales V, Hernandez MJ. On the demonstration of the Young- Laplace equation in introductory physics courses. Phys Educ 2000; 35: 126-129.

37. Partsch H. The static stiffness index: a simple method to assess the elastic property of compression material in vivo. Dermatol Surg 2005; 31: 625-630.

38. Partsch H. The use of pressure change on standing as a surrogate measure of the stiffness of a compression bandage. Eur J Vasc Endovasc Surg 2005; 30: 415-421.

39. Partsch H. Compression therapy in leg ulcers. Reviews in Vascular Medicine 2013; 1: 9-14.

40. Partsch H. Compression therapy of venous ulcers. EWMA JOURNAL 2006; 2: 16-20.

41. Reynolds $S$. The impact of a bandage training programme. JWC 1985; 8: 55-60.

42. Nelson EA et al. Improvements in bandaging technique following training. JWC 1995; 4: 181-184.

43. Keller A, Müller ML, Calow T, Kern IK, Schumann $\mathrm{H}$. Bandage pressure measurement and training: simple interventions to improve efficacy in compression bandaging. Int Wound J 2009; 6: 324-330.

44. Zarchi K et al Delivery of Compression Therapy for Venous Leg Ulcers. JAMA Dermatol 2014; 150: 730-736.

45. Protz K et al. Compression therapy: scientific background and practical applications. JDDG 2014: 794-801.

46. Mosti G, Partsch H. Is low compression pressure able to improve venous pumping function in patients with venous insufficiency? Phlebology. 2010 Jun; 25(3): 145-150.

47. Mosti G, Partsch H. Inelastic bandages maintain their hemodynamic effectiveness over time despite significant pressure loss. J Vasc Surg 2010 Oct; 52(4): 925-931.

48. Mosti G, Crespi A, Mattaliano V. Comparison Between a New, Two-component Compression System With Zinc Paste Bandages for Leg Ulcer Healing: A Prospective, Multicenter, Randomized, Controlled Trial Monitoring Sub-bandage Pressures. Wounds 2011; 23, 5: 126-134.

49. Mosti G, Rossari S. L'importanza della misurazione della pressione sottobendaggio e presentazione di un nuovo strumento di misura. Acta Vulnol 2008; 6: 31-36.

50. Partsch H, Mosti G. Comparison of three portable instruments to measure compression pressure. Int Ang 2010 Oct; 29(5): 426-430.

51. Mosti G, Mattaliano V, Partsch H. Influence of different materials in multicomponent bandages on pressure and stiffness of the final bandage. Dermatol Surg 2008; 34: 631-639.

52. Partsch H. Variability of interface pressure exerted by compression bandages and standard size compression stockings. Proceedings of 20th Annual Meeting of American Venous Forum. Charleston 20-23/February/2008.

53. Moffat C. Variability of pressure provided by sustained compression. Int Wound J 2008 Jun; 5(2): 259-265.

54. Milic DJ, Zivic SS, Bogdanovic DC, Jovanovic MM, Jankovic RJ, Milosevic ZD, Stamenkovic DM, Trenkic MS.The influence of different sub-ban- 
dage pressure values on venous leg ulcers healing when treated with compression therapy. J Vasc Surg 2010 Mar; 51(3): 655-661.

55. Harding $\mathrm{K}$ et al. Simplifying Venous Leg Ulcer Management. Wound International 2015.

56. Fife CE et al. Why is it so hard to do the right thing in wound care? Wound Rep Reg 2010; 18: $154-158$.

57. Spence RK, Cahall E. Inelastic versus elastic leg compression in chronic venous insufficiency: a comparison of limb size and venous hemodynamics. J Vasc Surg 1996 Nov; 24(5): 783-787.

58. Murthy G, Ballard RE, Breit GA, Watenpaugh DE, Hargens AR. Intramuscular pressures beneath elastic and inelastic leggings. Ann Vasc Surg 1994 Nov; 8(6): 543-548.

59. Damstra R, Partsch H. Prospective, randomized, controlled trial comparing the effectiveness of adjustable compression Velcro wraps versus inelastic multicomponent compression bandages in the initial treatment of leg lymphedema J Vasc Surg: Venous and Lym Dis 2013; 1: 13-19.

60. Mosti G, Partsch H. Self-management by firm, non-elastic adjustable compression wrap device. Veins and Lymphatics 2017; 6: 7003.

61. Blecken SR, Villavicencio JL Comparison of elastic versus nonelastic compression in bilateral venous ulcers: a randomized trial. J Vasc Surg 2005; 42: 1150-1155.

62. DePalma RG, Kowallek D, Spence RK, Caprini JA, Nehler MR, Jensen J, Goldman MP. Comparison of Costs and Healing Rates of Two Forms of Compression in Treating Venous Ulcers. Vasc Surg 1999; 33: 683-690.

63. Ehmann S, Whitaker JC, Hampton S, Collarte A. Multinational, pilot audit of a Velcro adjustable compression wrap system for venous and lymphatic conditions. J Wound Care 2016; 25: 513-520.

64. Mosti G, Cavezzi A, Partsch H, Urso S, Campana F. Adjustable Velcro $\left(^{\circ}\right)$ Compression Devices are More Effective than Inelastic Bandages in Reducing Venous Edema in the Initial Treatment Phase: A Randomized Controlled Trial. Eur J Vasc Endovasc Surg 2015; 50: 368-374.

65. McDaniel HB, Marston WA, Farber MA, Mendes RR, Owens LV, Young ML, et al. Recurrence of chronic venous ulcers on the basis of clinical, etiologic, anatomic, and pathophysiologic criteria and air plethysmography. J Vasc Surg 2002; 35: 723-728.

66. Gohel MS, Barwell JR, Taylor M, Chant T, Foy C, Earnshaw JJ et al. Long term results of compression therapy alone versus compression plus sur- gery in chronic venous ulceration (ESCHAR): Randomised controlled trial. BMJ 2007; 335: 83.

67. Howard DPJ, Howard A, Kothari A, Wales L, Guest M, Davies AH. The Role of Superficial Venous Surgery in the Management of Venous Ulcers: A Systematic Review. Eur J Vasc Endovasc Surg 2008; 36: 458-465.

68. Nelson EA, Harper DR, Prescott RJ, Gibson B, Brown D, Ruckley CV. Prevention of recurrence of venous ulceration: randomized controlled trial of class 2 and class 3 elastic compression. J Vasc Surg 2006 Oct; 44(4): 803-808.

69. Clarke-Moloney M, Keane N, O‘Connor V, Ryan MA, Meagher H, Grace PA, Kavanagh E, Walsh SR, Burke PE. Randomised controlled trial comparing European standard class 1 to class 2 compression stockings for ulcer recurrence and patient compliance. Int Wound J 2014 Aug; 11(4): 404-408.

70. Partsch H, Menzinger G, Mostbeck A. Inelastic leg compression is more effective to reduce deep venous refluxes than elastic bandages. Dermatol Surg 1999 Sep; 25(9): 695-700. 